\title{
Motorboat noise can potentially mask the whistle sound of estuarine dolphins (Sotalia guianensis)
}

\author{
Natalia de Souza Albuquerque ${ }^{1}$ and Antonio da Silva Souto ${ }^{2, *}$ \\ ${ }^{1}$ Universidade de São Paulo, Instituto de Psicologia, Departamento de Psicologia Experimental, \\ Avenida Professor Mello Moraes, 1721, Cidade Universitária, 05508-030, São Paulo, São Paulo, \\ Brazil. \\ ${ }^{2}$ Universidade Federal de Pernambuco, Centro de Ciências Biológicas, Departamento de Zoologia, \\ Avenida Professor Moraes Rego S/N, Cidade Universitária, 50670-420, Recife, Pernambuco, Brazil. \\ ${ }^{*}$ Corresponding author \\ $\bowtie$ E-mail address: asouto.labet@gmail.com
}

Ethnobiology and Conservation 2013, 2:5 (03 June 2013)

ISSN 2238-4782

doi: 10.15451/ec2013-8-2.5-1-15

ethnobioconservation.com

\begin{abstract}
Masking the sounds uttered by cetaceans is an important issue in underwater noise pollution produced by vessels. This research aimed to determine whether noises produced by the engines of tourism boats can mask whistles emitted by estuarine dolphins (Sotalia guianensis). Data collection was conducted at Baía dos Golfinhos (English: Dolphin Bay) (Rio Grande do Norte, Brazil), an area mainly used for foraging by these animals. We recorded underwater vocalizations of the animals and the sound generated by motorboats in the Bay using equipment capable of capturing sounds with frequencies up to $40 \mathrm{kHz}$. Sound amplitude was compared at $6,10,16$ and $30 \mathrm{kHz}$. We also observed the boats activity in the area. The results showed that the noise produced by motorboats can reach frequencies of up to $40 \mathrm{kHz}$ (average: petrol $=17.1 \mathrm{kHz}, \pm 8.4$; diesel $=13.1 \mathrm{kHz}, \pm 4.9$ ) and is similar to the whistles uttered by the estuarine dolphin (up to $35 \mathrm{kHz}$; average: $19 \mathrm{kHz}, \pm 6.2$ ). The sound amplitude also reached similar values at the frequencies of $6,10,16$ and $30 \mathrm{kHz}$ for petrol engines, and $6 \mathrm{kHz}$ for diesel motorboats (whistles were higher at 10 and $16 \mathrm{kHz}$ ). Thus, engine noise is a potential source of disturbance to the whistles uttered by these cetaceans. Even the presence of one tourism boat can potentially interfere with the communication between individuals and, as a consequence, on the performance of natural behaviours. Thus, our results can help to explain previous studies on estuarine dolphins that found behavioural disturbances in the presence of tourism boats. In addition, such findings are in accordance with a number of studies on other cetacean species that recorded negative impacts caused by motorboats. As a precautionary measure, a number of areas constantly used by the estuarine dolphins, such as the Baía dos Golfinhos, should be closed to motorboat traffic. This would minimize the negative impact caused by human activities on the welfare and conservation of the estuarine dolphins.
\end{abstract}

Keywords: Animal welfare - Conservation - Communication - Noise pollution Sound disturbance - Tourism boats 


\section{Introduction}

Cetaceans use sounds in different situations and for different purposes, and hearing is their main sense (Weilgart 2007a,b). Vocalizations are emitted in danger situations, during prey pursuit, to indicate position, identity, territory and social status (Richardson et al. 1995), as well as being essential in the coordination of behaviour and to maintain group cohesion (Richardson et al. 1995; Buckstaff 2004; RossiSantos and Podos 2006; David 2006; May-Collado and Wartzok 2008).

Disturbances in their vocal behaviour may cause a reduction in their ability to find food, navigate and communicate with other members of the population (Richardson et al. 1995; Lesage et al. 1999; Foote et al. 2004; Holt et al. 2012; Noren et al. 2012). In turbid water especially, dolphins use acoustic signals to maintain contact with other individuals in the group (Van Parijs and Corkeron 2001). There seems to be no doubt that acoustic studies of dolphins in free environments are beneficial to conservation (Pivari and Rosso 2005; Laiolo 2010) and also welfare.

Most tourism based on cetacean watching is done using motorboats (Parsons 2012) and the sound generated by the petrol and diesel engines should be a primary concern to those who study cetaceans (Constantine 1999). Some of the effects of underwater noises are increased stress levels, the abandonment of areas, and the masking of natural sounds of biological importance (Weilgart 2007a; Parsons 2012). The acoustic phenomenon called masking refers to the interfering or obscuring effects of noise, which limits animal communication (Weilgart 2007a). Masking can both reduce the range over which signals can be heard and reduce the signal's quality of information (Weilgart 2007b). Masking occurs when the signal and the masking sound have similar frequencies and amplitude, and overlap or temporally occur very close to each other (Branstetter and Finneran 2008). Although very important for welfare and conservation efforts, studies of the masking effect on dolphins' communication are still relatively scarce.

The estuarine dolphin (Sotalia guianensis; Van Bénéden, 1864) is known for its elusive behaviour (Simão et al. 2000), and unlike some other dolphin species, it avoids proximity to boats (Lodi 2003). However, its preference for coastal waters renders this species vulnerable to many human activities that threaten its welfare and conservation (Lodi 2003). In addition, it shows site fidelity (Flores 1999; Santos et al. 2000; Rossi-Santos et al. 2007; Araújo et al. 2008; Nery et al. 2008), a factor that increases its vulnerability to human sources of disturbance (Carrera et al. 2008). However, a shortage of ecological studies currently hampers any assessment concerning the conservation status of this species (Secchi 2012). Thus, the estuarine dolphin is classified as "Data Deficient" by the IUCN (Secchi 2012).

As for the disturbance motorboats can cause to estuarine dolphins at Baía dos Golfinhos (Rio Grande do Norte, Brazil), it is already known that they can clearly change the behaviour of these cetaceans. Valle and Melo (2006), for example, concluded that the activity of motor boats cause individuals to get physically closer to each other. They hypothesized that the noise produced by the engines could disturb their communication, and being close in a murky environment could be a way to facilitate communication. Carrera et al. (2008) showed that tourism motorboats reduce foraging activity and displace these cetaceans from the Bay; the authors hypothesized that the noise produced by motorboats disturbed the dolphins.

Although such studies are effective in showing the disturbance caused by tourism motorboats, they commonly do not demonstrate more precisely how motor boats are harmful to dolphins. As it is known that estuarine dolphins' whistles are 
used in a large number of behavioural contexts (Rossi-Santos and Podos 2006) such as cooperative foraging (Nowacek 2005), it is indeed likely that motor boat noise can disturb their behaviours by masking such sounds. Rezende (2008) in Cananéia (São Paulo, Brazil) using equipment able to record upper frequencies limited to $22 \mathrm{kHz}$ highlighted the masking potential of the noise from motorboats, as the animals tend to reduce the emission of sounds when a vessel is passing by. An unpublished study in Baía dos Golfinhos using ultrasound equipment also suggests a masking effect at higher frequencies (Martins 2010). In spite of their importance, both studies were carried out from motorboats, which may act as a confounding factor by increasing the animals' overall exposure to vessels and, thus, induce changes in their postural and vocal behaviour (Bejder et al. 1999; Bejder and Samuels 2003; Bejder et al. 2006).

The importance of conducting and publishing studies on the phenomenon of masking cannot be overstated. These two combined actions provide the scientific community and environmental agencies crucial information for further investigations and decision making concerning protective measures. Therefore, this research aimed to investigate the potential masking of noise produced by the engines of tourism boats on the whistles emitted by estuarine dolphins. For this purpose, equipment capable of recording ultrasound was employed, and the use of motorboats to collect data was avoided. Moreover, it was part of the investigation to determine the number of motorboats simultaneously in the Bay, the amount of time they remained in activity at the site, and their distance from the dolphins.

\section{Methodology}

This study is noninvasive and complies with Brazilian law. All data collection was conducted at Baía dos Golfinhos (English: Dolphin Bay), located at Praia da Pipa (Pipa Beach), municipality of Tibau do Sul $\left(6^{\circ} 10 \mathrm{~S}, 35^{\circ} 05 \mathrm{~W}\right)$, state of Rio Grande do Norte, Brazil. Baía dos Golfinhos is known for the frequent sightings of Sotalia guianensis dolphins and for cetacean observation activities from motorboats (whale watching). It is a protected area, part of the Tibau do Sul Coastal Fauna Reserve. The Bay has approximately $0.4 \mathrm{~km}^{2}$ in area and is characteristically surrounded by cliffs (Carrera et al. 2008). The maximum depth (7 metres) is reached at the exit of the Bay (Garri 2006). The water temperature ranges from $19^{\circ} \mathrm{C}$ to $28^{\circ} \mathrm{C}$ and salinity between 36 and 37\% (Souto et al. 2006). The water is turbid, as a result of moderate waves, small particles of soil, low depth and erosion caused by waves when they reach the cliffs (Souto et al. 2006). The topography and structure of the Bay ensure good conditions for these small cetaceans that seem to prefer calm waters (Souto et al. 2006).

The main use of the area by estuarine dolphins is for feeding (Araújo et al. 2003). The average number of dolphins in the Bay varies from $2.77( \pm 0.17)$, when boats are present, to $3.3( \pm 0.18)$ when boats are not visiting the site (Carrera et al. 2008). These authors clearly identified at least eight individuals via differences (distinctive marks) in dorsal fins at Baía dos Golfinhos.

Eight boats of three types are in activity in the Bay: schooners (two), fishing boat adapted for tourism (one) and motorboats (five). Schooners and fishing boats have a 6cc diesel engine, while motorboats, smaller boats, have a two-stroke petrol engine with outputs of 40,60, 70 and $115 \mathrm{HP}$. 


\section{Procedures}

\section{General procedure}

It is not an easy task to observe the behaviour of dolphins in their natural environment (Bejder and Samuels 2003) and when they live in murky waters this becomes even harder (eg Carrera et al. 2008). Such difficulty is especially clear when the objective is to investigate possible disturbances in their communication, caused by environmental noise. Ideally, the researcher should be in a position to perceive that the animal (receiver) is unable to hear or to understand the vocal signs uttered by another individual. Due to the difficulty in accessing such information the present study limited its scope to investigating the potential effect of engine noises on masking dolphins' communication. As such, this study relies on the following indicators for potential masking: whistle and engine noises must occur at the same location and time, and both must share overlapping physical qualities. The boat activity in the Bay is also important: if it pursues the dolphins or gets positioned in between members of a group, then the noise produced will probably make the communication between individuals more difficult.

\section{Sound recordings and analyses}

In February 2009, we recorded underwater estuarine dolphin vocalizations, the sound generated by boats and the ambient noise in the Bay. The recordings were made with an underwater sound recording system model SQ26-MT (Cetacean Research Technology Inc.), consisting of a hydrophone, model SQ26-08 connected to a portable recorder (M-Audio MicroTrack II-Professional) (sample rate: $96 \mathrm{kHz}$ at 16 bits signed). This equipment is capable of faithfully recording sounds up to $40 \mathrm{kHz}$ (Cetacean Research Technology Inc.).

So far, all bioacoustics studies focusing on Sotalia guianensis have been conducted from motorboats. It has been suggested that even with the engine turned off at the time of recording, the presence of the boat can cause interference and result in changes in the communication of dolphins (Bejder et al. 1999). Thus, the use of boats for research purposes must be carefully measured (Nowacek and Tyack 2001; Lusseau 2003; Constantine et al. 2004). It is also worth noting that even on occasions when there is already a motorboat in activity in the study site, the presence of the researcher's vessel may act as an additional stimulus and should be avoided when possible (eg Carrera et al. 2008). To avoid such interference, the data collection was performed without the use of boats. We entered the water by the beach and stayed still at a distance of approximately 15 metres from the seashore (depth: 1.5 metres). The hydrophone was submerged at a depth of $50 \mathrm{~cm}$. This method was feasible, because the waters in the Bay are shallow and calm. The observer could then stand firmly and perform the recordings without constraints. It was not possible to determine the identity of the vocalizing dolphin or its distance from the recording device. However, the distance between the recording device and the dolphins (spotted using their dorsal fins and upper body) was usually in a range estimated as 5 to 40 metres; the distance from the device to the boats was estimated as 10-75 metres. Thus, the results in this study are rather conservative, as the recording equipment tended to be further from the motorboats than from the dolphins. 
Sampling effort corresponded to a total of 16 hours (over four consecutive days), from which we obtained three hundred and ninety-eight minutes of usable recordings. From these recordings we extracted a total of 339 whistles and 61 sounds produced by the engines of the motorboats. Due to the sample size, the sampling time was deemed sufficient to study the potential masking effect of the noise produced by motorboats on the whistles uttered by the dolphins. The recordings were performed during periods of low tide when the Bay becomes accessible by land. The recorded wav files of the sounds were transferred to a PC based computer and edited with the Audacity 1.3 software (GNU General Public License version 2.0).

The physical analyses of the dolphin sounds covered the start, end, minimum and maximum frequencies, sound amplitude (highest level at $6,10,16$ and $30 \mathrm{kHz}, \pm$ $50 \mathrm{~Hz}$ ), as well as frequency range, duration and form of whistling. All physical analyses of the sounds, with exception of amplitude, were made via Syrinx software (J. Burt, Seattle, Washington). Settings for the spectral analyses, when using Syrinx: window type = Blackman; FFT size $=256$ samples; spectral gain $=0$; white threshold = 0; grayscale = black-on-white. Sound amplitude $(\mathrm{dB})$ was measured via Raven Pro 1.4 software (The Cornell Lab of Ornithology). Settings for the spectral analyses of amplitude (Raven software): window type = Hann; DFT size $=256$ samples; grid spacing $=375 \mathrm{~Hz}$; overlap coefficient $=50 \%$; colour map = grayscale; brightness and contrast $=50 \%$. All whistle analyses were made taking into account the fundamental frequency only. It is worth noting that not all recorded whistles could be used for the amplitude analysis as some of them were not uttered in the four frequencies chosen, i.e., 6, 10, 16 and $30 \mathrm{kHz}$. These frequencies were chosen because they should cover a great number of the estuarine dolphins' whistle types. We chose the highest amplitude within each of the four frequencies for later amplitude comparisons with the motorboats. For the motorboats, the sound amplitude for both engine types (diesel and petrol) was estimated at $6,10,16$ and $30 \mathrm{kHz}( \pm 50 \mathrm{~Hz})$. For measuring the sound amplitude from boats we selected small areas of the spectrogram at each specified frequency and measured its maximal power. Areas in which spurious click sounds could be perceived were avoided. Such clicks of undetermined origin occurred at completely irregular intervals (different from those produced by dolphins) (e.g. Mortesen et al. 2011) and were easily recognizable. The sample size for each frequency varied because not all recorded sounds covered the specified frequencies, possibly due to the unmeasured speed of the vessels and distance from the recording device. In addition, because more than one vessel can be simultaneously active in the Bay, which can be a confounding factor for sound analysis, we only considered situations in which one motorboat was present. We also investigated the highest frequency produced by the petrol and diesel engines. As for the lowest frequencies of both types of vessels, they reached levels similar to those of other unidentified ambient noise, and hence we did not measure this physical characteristic. For ambient noise we measured the amplitude at the four specified frequencies. Detectable sounds of dolphins, motor boats and spurious clicks were not present during such analysis.

\section{Motorboat activities}

We conducted the observations in February and March 2009 for eight hours a day (from 8:00 to 16:00) over a period of 19 days (totalling 168 hours of effective 
effort). Observations were made from a fixed point located at the top of a cliff, at a height of about 20 metres and at an approximate distance of between 30 to 80 metres from the sea (high and low tide, respectively).

We analysed the following parameters: number of days on which boats entered the Bay, frequency of visits made by the boats and how many were present at the same time, the time of use of the Bay by the dolphins (with and without the presence of boats); schedules, within the day, when there was greater boat traffic and time of use of the Bay by boats. In addition, possible events of pursuit were recorded (short distances kept by boats in relation to dolphins). We made the estimation of the two distances ( $<50$ metres and $\geq 50$ metres) using physical and geographical marks following the method used by Carrera et al. (2008). We discarded all cases in which an estimation could not be made. Estimated distances between physical and geographical marks were verified using a laser rangefinder (Bushnell Sport 450; Bushnell Performance Optics).

\section{Data analysis}

When appropriate we estimated the average and the standard deviation (SD) for the collected data. We employed the Kruskal-Wallis one-way analysis of variance by ranks, followed by the Dunn's test, to test differences between the energy of the sounds produced by motorboats (petrol and diesel engines), dolphins (whistles) and ambient sound. Careful interpretation of the statistical results is necessary because the identity of the vocalizing dolphins and their distance to the recording device could not be determined. Thus, the same dolphin possibly has contributed more than once to the collected data. This is certainly valid for the eight motor boats in continuous activity at the site. Moreover, the parameter sound energy varies with distance and while neither dolphins nor motorboats had a fixed location in the Bay recordings were performed at a fixed point in the water. Several studies dealing with free-living animals have had similar problems (Weary \& Fraser 1998; Rook 1999; Mundry \& Sommer 2007), and the best solution seems to be the completion of studies on the subject by different researchers in different sites (Johnson 1999; eg Carrera et al. 2008). Statistical significance was attained when $p \leq 0.05$ (two-tailed).

\section{Results}

\section{Motorboat activities}

We recorded motorboats in Baía dos Golfinhos on all days of data collection ( $\mathrm{n}$ $=19$ ). In most events of presence of motorboats there were simultaneously one or to two boats in the Bay $(428 ; 77 \%)$ and although to a lesser extent we also recorded three to six boats at the same time $(129 ; 23 \%)$.

During 19 days, we registered 1246 events of boat entries into the Bay with an average of 66 daily events, which were distributed throughout the day. Entries were not dependent on tide and were more common between 10:00 and 14:00 (80\% of all events) than during the earlier and latter hours of the day combined (8:00-10:00 and 14:00-16:00; 20\%). In total, boats spent 6062 minutes in the Bay, with an average time of boat exposure of $46( \pm 41)$ consecutive minutes and a daily average stay of $319( \pm 45.49)$ minutes. It was observed that boats were present $54 \%$ of the time (1864 minutes) during which the dolphins used the Bay. 
Moreover, it was found that in $95 \%$ of cases (105 out of 110 records), the boats were closer than 50 metres from the dolphins.

\section{Whistle frequencies}

We obtained values from 1.32 to $23.99 \mathrm{kHz}$ (mean: $9.79 \mathrm{kHz}, \pm 3.22$ ) for whistles' start frequencies, the majority (39.7\%) within the range from 8 to $11.99 \mathrm{kHz}$ and the minority (0.3\%) from 20 to $23.99 \mathrm{kHz}$ (Figure 1). We have also registered end frequencies that reached up to $34.87 \mathrm{kHz}$ (mean: $19.08 \mathrm{kHz}, \pm 6.12 ; 4.4 \%$ with frequencies above $30 \mathrm{kHz}$ ); $22.6 \%$ of whistles showed end frequencies ranging from 16 to $19.99 \mathrm{kHz}$, while $0.3 \%$ showed end frequencies between 2.87 and $3.99 \mathrm{kHz}$. $45.8 \%$ of whistles showed minimum frequencies between 4 and $7.99 \mathrm{kHz}$ (mean: $8.76 \mathrm{kHz}, \pm 2.88)$ and $23.3 \%$ showed maximum frequencies between 16 and 19.99 $\mathrm{kHz}$ (mean: $19.33 \mathrm{kHz}, \pm 6.03$ ). Moreover, it was found that $20.3 \%$ of whistles had maximum frequencies above $24 \mathrm{kHz}$. We also recorded whistles with frequency ranges from 0.42 to $28.74 \mathrm{kHz}$; the majority (56\%) and minority (12\%) concentrated at intervals from 0.42 to 9.99 and from 20 to $28.74 \mathrm{kHz}$, respectively (mean: 10.57 $\mathrm{kHz}, \pm 7.13$ ). Whistles' duration ranged from $20.6 \mathrm{~ms}$ to $602 \mathrm{~ms}$, with an average of $217 \mathrm{~ms}\left(\mathrm{n}=339_{-} \pm 137\right)$. The results of sound recordings revealed different types of whistles, which were separated here into three major groups. Most are ascending $(88 \%)$ composed of different numbers of inflection points, followed by descendingascending (9\%) and others (3\%).

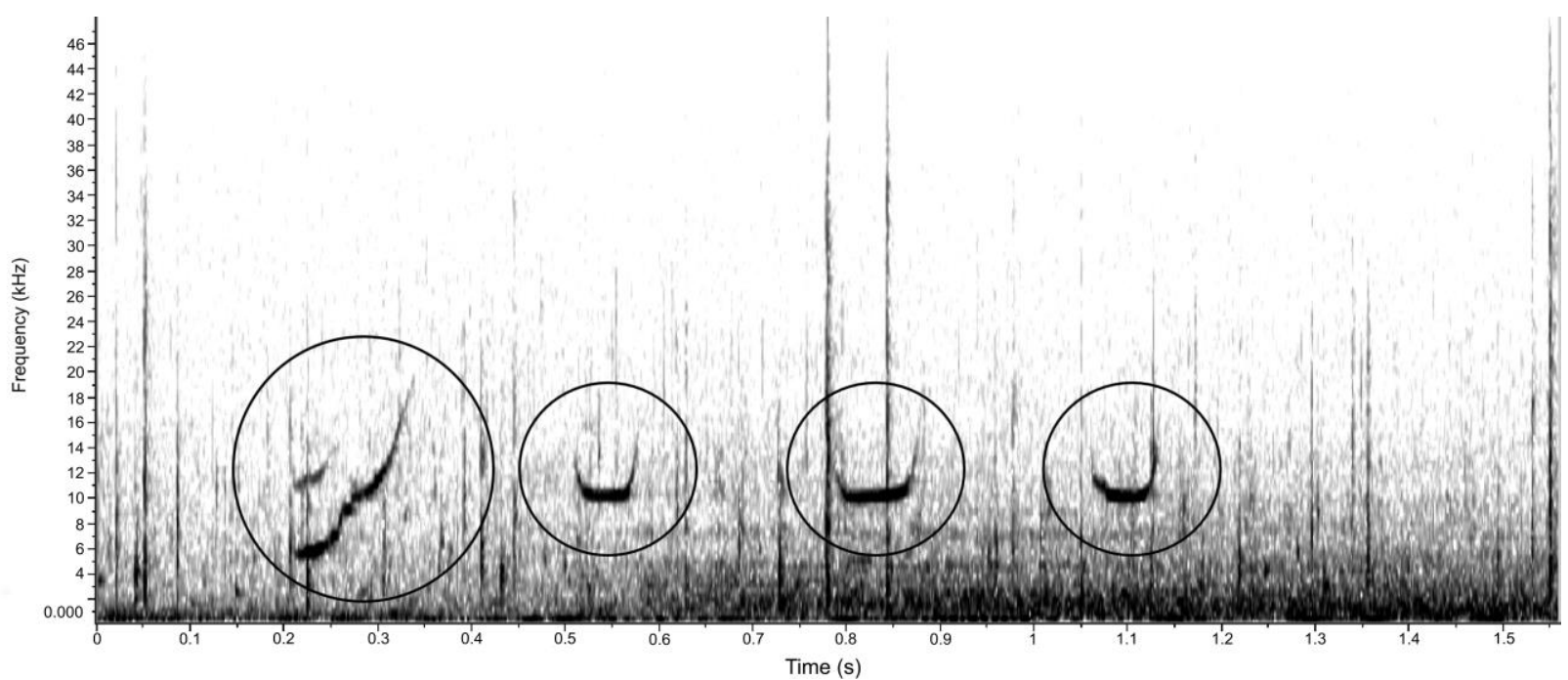

Figure 1. Sonogram of four whistles of two types (inside the dark circles) uttered by one or more estuarine dolphins at the study site. In this example the highest frequency reached $20 \mathrm{kHz}$ (end frequency of the first whistle, from the left). First whistle (larger circle) = ascending type; inside the smaller circles are descending-ascending whistles. Window type = Hann; DFT size = 256 samples; grid spacing $=375 \mathrm{~Hz}$; overlap coefficient $=50 \%$.

\section{Motorboats' noise frequencies}

We recorded a continuous type of noise produced by the two classes of motorboats (petrol and diesel). The average highest frequency generated by petrol motorboats was equal to $17.1 \mathrm{kHz}(\mathrm{n}=41$; \pm 8.4$)$ and diesel motorboats, $13.1 \mathrm{kHz}(\mathrm{n}$ $=20 ; \pm 4.9$ ) but the sounds of the two classes could also reach frequencies that entered the upper limit of the recording device $(40 \mathrm{kHz})$, although lacking strength at 
this level (Figure 2 for an example). According to those results and the sonogram analysis, motorboat noise can potentially mask the dolphin whistles, as the sonograms of those two sounds overlap (Figure 3).

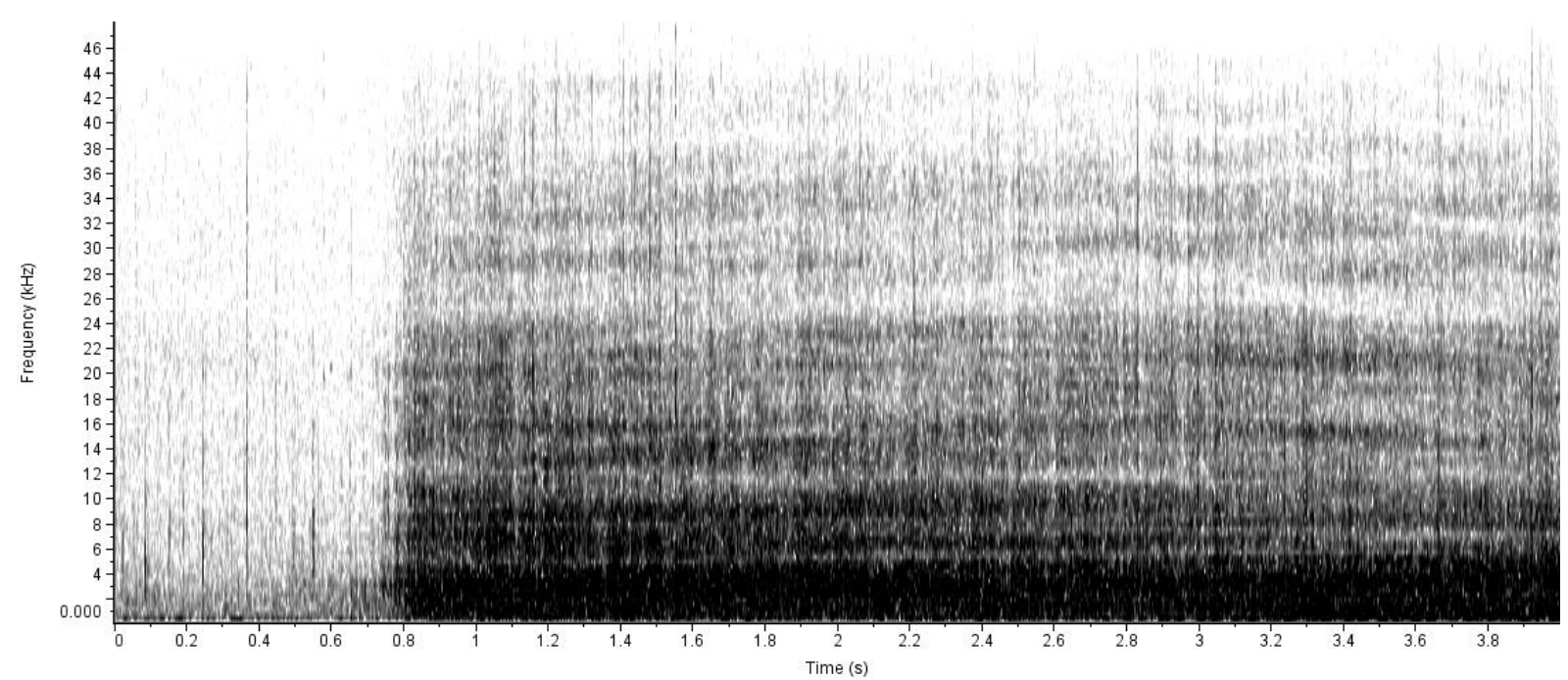

Figure 2. Sonogram of the sound produced by a motorboat when engine is started (noise beginning at 0.7 seconds). In this case, noise frequency goes clearly above $20 \mathrm{kHz}$. Window type = Hann; DFT size $=256$ samples; grid spacing $=375 \mathrm{~Hz}$; overlap coefficient $=50 \%$.

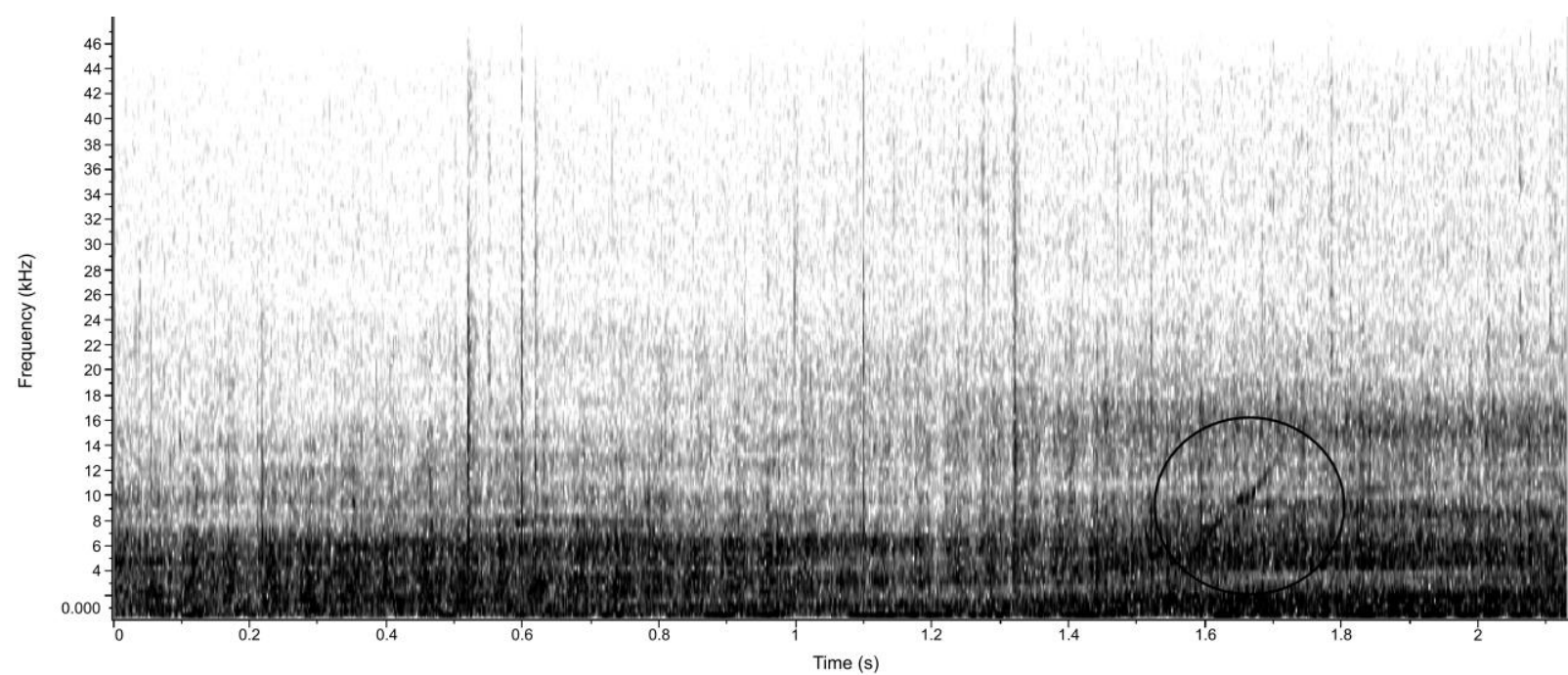

Figure 3. Sonogram showing the motor noise (dark band up to $18 \mathrm{kHz}$ ) masking effect, in relation to the recording device, on the whistle of an estuarine dolphin at the study site. In this case the sonogram still shows a fragment of the represented vocalization (ascending type, inside black circle). Window type $=$ Hann; DFT size $=256$ samples; grid spacing $=375 \mathrm{~Hz}$; overlap coefficient $=50 \%$.

\section{Sound amplitude of whistles, motorboat noise and underwater ambient sound}

At $6 \mathrm{kHz}$ there was no significant difference between the noise from the motorboats and the whistle uttered by the dolphins; ambient sound produced significantly lower amplitude than the other sources $(K W=56.52, N=133, p<$ 0.0001; petrol motor boats versus whistles: $p>0.05$; diesel motorboats versus whistles: $p>0.05$; petrol motorboats versus diesel: $p>0.05$; petrol motorboats versus ambient sound: $p<0.001$; diesel motorboats versus ambient sound: $p<$ 
0.001; whistles versus ambient sound: $\mathrm{p}<0.001$; Figure 4). At $10 \mathrm{kHz}$ the amplitude from the whistles was significantly higher than the noise produced by diesel engines, but no difference was found between the former and the noise from petrol engines. At this frequency there was also no difference between the noise from diesel and petrol engines; ambient sound produced significantly lower amplitude than the other sources $(K W=66.36, N=211, p<0.0001$; petrol motorboats versus whistles: $p>$ 0.05 ; diesel motorboats versus whistles: $p<0.01$; petrol motorboats versus diesel: $p$ $>0.05$; petrol motorboats versus ambient sound: $p<0.001$; diesel motorboats versus ambient sound: $p<0.001$; whistles versus ambient: $p<0.001$; Figure 4). At $16 \mathrm{kHz}$ the results were similar to those found at $10 \mathrm{kHz}$. However, there was no statistical difference between the sound produced by diesel motorboats and ambient sound $(\mathrm{KW}=75.39, \mathrm{~N}=135, \mathrm{p}<0.0001$; petrol motorboats versus whistles: $\mathrm{p}>0.05$; diesel motorboats versus whistles: $p<0.001$; petrol motorboats versus diesel: $p>0.05$; petrol motorboats versus ambient sound: $p<0.001$; diesel motorboats versus ambient sound: $p>0.05$; whistles versus ambient sound: $p<0.001$; Figure 4). At 30 $\mathrm{kHz}$ the results were similar to those found at $6 \mathrm{kHz}$, with the exception of diesel motorboats: too few data points were obtained for this kind of vessel at $30 \mathrm{kHz}(\mathrm{KW}=$ $35.80, N=51, p<0.0001$; petrol motorboats versus whistles: $p>0.05$; petrol motorboats versus ambient sound: $p<0.001$; whistles versus ambient sound: $p<$ 0.001 , Figure 4). Figure 5 shows the overlapping of sound power spectra for diesel and petrol boat noise, ambient noise and two typical whistles.

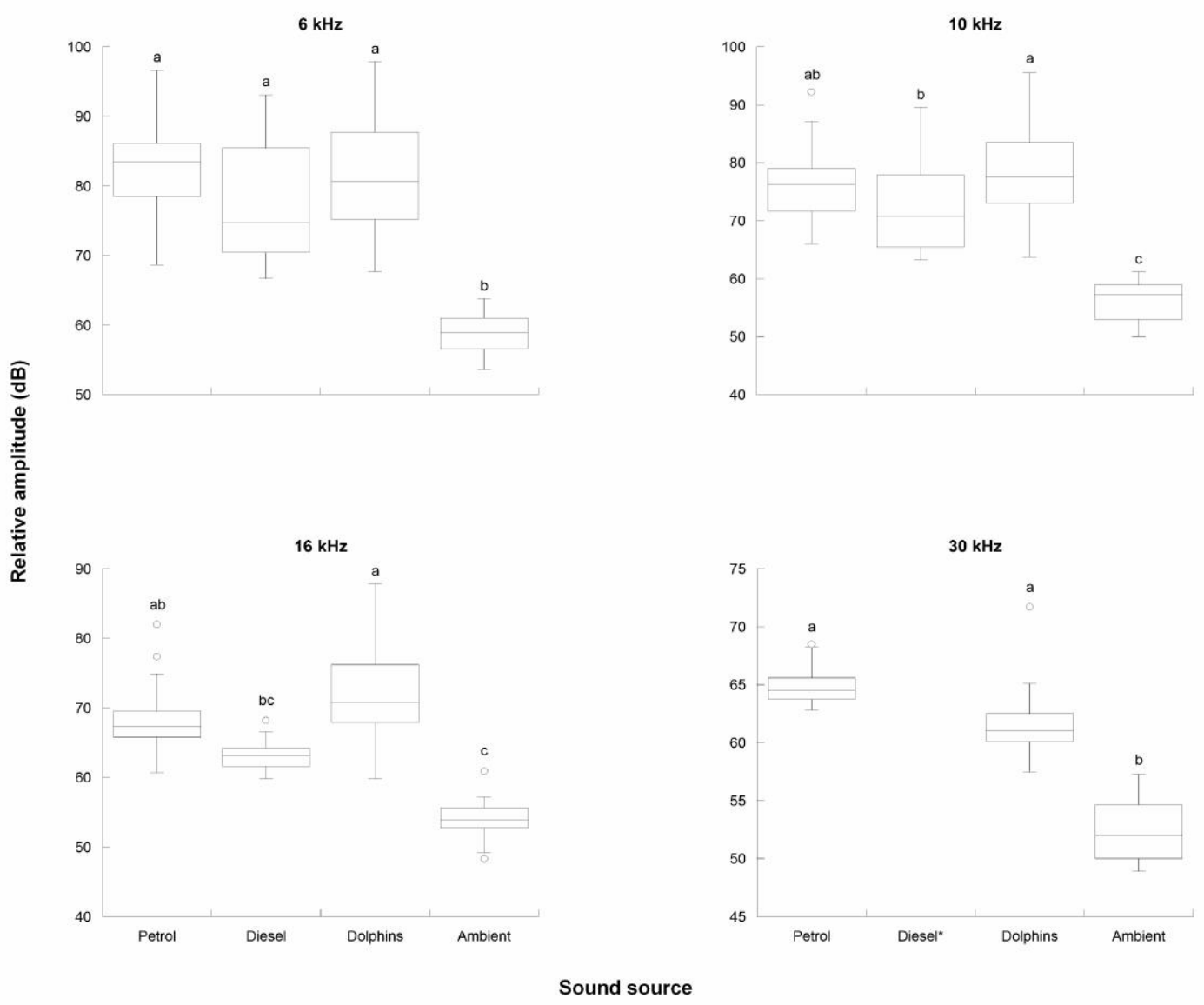

Figure 4. Sound amplitude of petrol engines and the whistle call are statistically similar across the four studied frequencies; sound amplitude of diesel engines is similar at $6 \mathrm{kHz}$ (too few data points prevented calculations at $30 \mathrm{kHz}$ ); all are significantly above other ambient sounds, with the exception of diesel at $16 \mathrm{kHz}$. Illustrated are medians and interquartile distances; bars represent maximum and 
minimum values of the dataset; outliers are represented by empty circles. Different letters $=p \leq 0.05$, similar letters $=$ non-significant $(p>0.05)$. Statistics: Kruskal-Wallis test (corrected for ties), followed by the Dunn's test. ${ }^{*}=$ too few data points at $30 \mathrm{kHz} ; \mathrm{dB}=$ decibels; $\mathrm{kHz}=$ kilohertz.

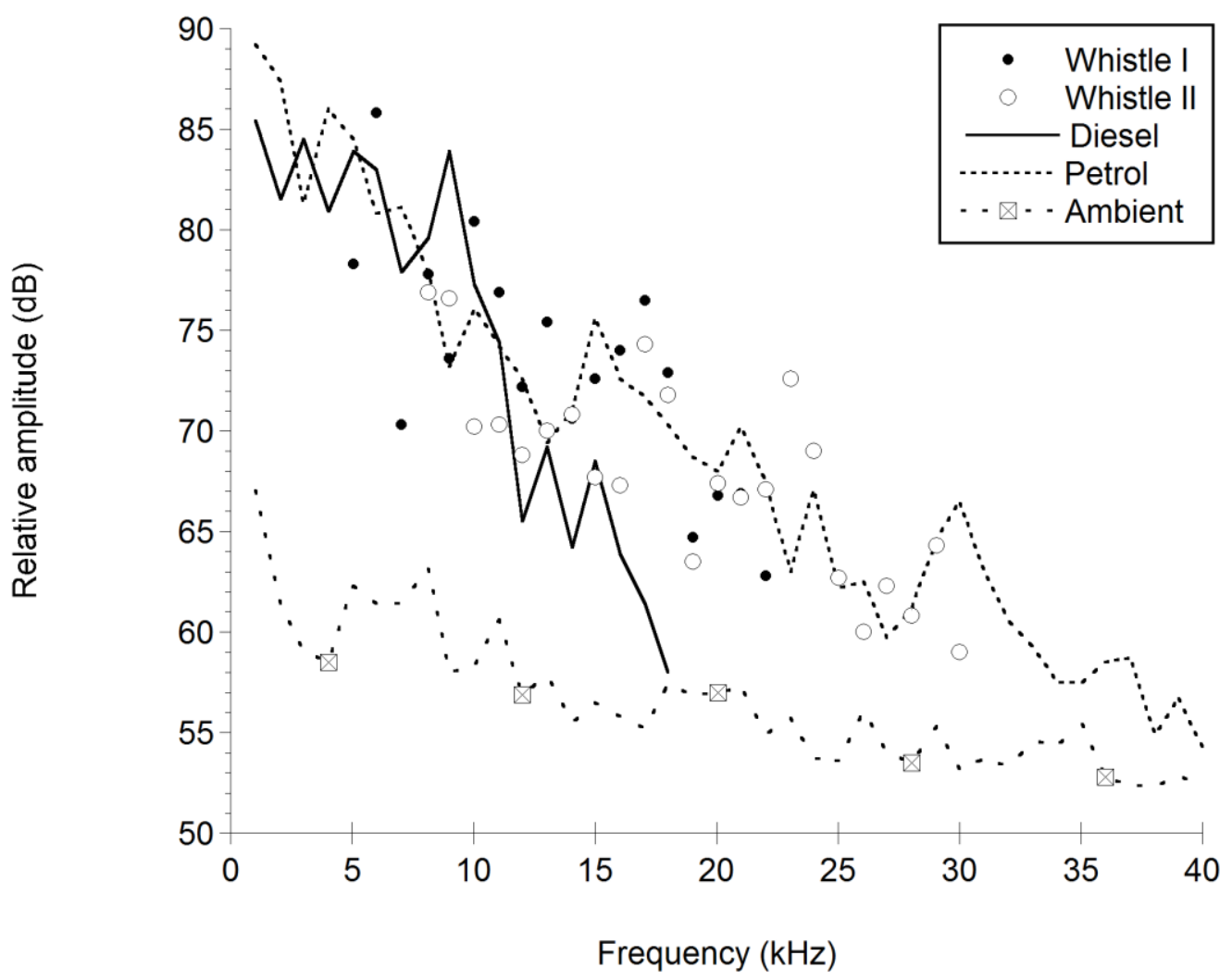

Figure 5. Power spectra across several frequencies (1 to $40 \mathrm{kHz}$ ) of two whistles, a diesel and a petrol motorboat, and ambient sound. Whistle I = 5 to $22 \mathrm{kHz}$; Whistle II = 7 to $30 \mathrm{kHz}$. $\mathrm{dB}=\mathrm{decibels}$; $\mathrm{kHz}=$ kilohertz.

\section{Discussion}

By using recording equipment that covers a wide spectrum of sound frequencies, and avoiding the use of motorboats during recordings, this research recorded whistles with fundamental frequencies that can be partially or totally overlapped by the noise produced by motorboats in Baía dos Golfinhos. Moreover, the recorded motorboat engines created a curtain of noise that can reach amplitude levels as high as the whistles uttered by the dolphins. Thus, the possibility of masking or obscuring this vocalization is evident, even at its highest frequency $(34.87 \mathrm{kHz})$. In Florida, Buckstaff (2004) recorded maximum frequencies for recreational boats equal to $12 \mathrm{kHz}$, and found that the boats were hampering the communication of bottlenose dolphins, which produced whistles with maximum frequencies up to $23 \mathrm{kHz}$ (upper limit of the employed recording device). Thus, motorboats in Baía dos Golfinhos produce sounds of frequency and energy levels sufficient to mask the whistles emitted by estuarine dolphins, which can disturb the local population, as described by Valle and Melo (2006; animals reacted to the presence of the motorboats by getting 
closer to each other, possibly to facilitate communication) and Carrera et al. (2008; animals were displaced from the site and foraging behaviour was reduced, possibly because they could not coordinate social activities adequately). Thus, it seems unlikely that estuarine dolphins communicating through whistles can adequately cope with engine sounds that can reach frequencies as high as $40 \mathrm{kHz}$ and similar energy levels at a variety of frequencies.

As for the boat activity, Van Parijs and Corkeron (2001) found that the acoustic communication of Sousa chinensis was significantly affected by boat traffic, with an average of one boat per hour. In Baía dos Golfinhos, the animals may be subject to interference of up to eight boats in periods of up to 46 consecutive minutes, indicating a potentially serious disturbance situation. There are eight boats operating in the region and the traffic at the Bay was characterized by 1246 events of entry of boats in 19 days, approximately 66 boats with tourists searching to meet the estuarine dolphins daily. The study by Foote et al. (2004), which recorded disturbance caused by the presence of motorboats on a group of killer whales, presents similar results to ours in terms of the average number of boats accompanying the group of animals daily, although the fleet comprised 72 boats. In addition, it was common to see boats between two or more individuals in Baía dos Golfinhos, a situation that can enhance the interference on their communication. Moreover, the usual proximity of the boats in relation to the estuarine dolphins (less than 50 meters) should be a cause of great concern. In fact, some studies with cetaceans have shown that sounds produced by boats caused interference even from a distance of 1.5 to $14 \mathrm{~km}$ (Foote et al. 2004; Van Parijs and Corkeron 2001; Bejder et al. 1999).

Artificial sources of underwater noise are more harmful to cetaceans than most sources of pollution (André 2009). Motorboat traffic is considered a major source of disturbance for these animals, being a problem to the welfare and conservation of the species (Goodwin and Cotton 2004). Any region directly affected by the impacts caused by tour boats, and predominantly used by dolphins for feeding, breeding, resting or socializing activities deserves to be prioritized by protection programs (Lusseau and Higham 2004). The interference caused by tour boats to dolphins must be the primary cause for concern with regard to the management of areas of occurrence of these animals. Considering that, Weilgart (2007a) suggested that precautionary measures should be applied to the management of these areas (eg Cooney 2004).

Baía dos Golfinhos is an area of importance for Sotalia guianensis, mainly for food supply (Araújo et al. 2003). As reported by Weilgart (2007b), disturbances in vocalization may lead to decreased efficiency in foraging. Thus, they should be allowed to conduct their activities with as little interference as possible, as negative influences on behaviours such as prey pursuit can lead to deleterious consequences for the animals (eg Bejder et al. 1999). The existence of a pervasive masking effect shows that recent local attempts to control the impact of boat tourism, by limiting the maximum number of visiting tourism boats (two) inside the Bay at the same time, although an advance, is not sufficient (eg Tosi and Ferreira 2009). In fact, Carrera et al. (2008) showed that the visit of one tourism motorboat at a time was enough to reduce the foraging behaviour of estuarine dolphins in Baía dos Golfinhos.

As with other cetacean species, the noise produced by the petrol and diesel engines of motorboats helps to explain the results found in Valle and Melo (2006) and in Carrera et al. (2008). Further, coupled with other studies that showed disturbances caused by motorboats (eg Lesage et al. 1999; Van Parijs and Corkeron 
2001; Foote et al. 2004; Jensen et al. 2009), our results call for precautionary measures (Weilgart 2007a; Cooney 2004) to protect the estuarine dolphins. A number of selected areas of similar importance to Baía dos Golfinhos should be closed to motorboats. This would help minimize the negative impacts caused by human activities on the welfare and conservation of estuarine dolphins. While this measure is not implemented, studies in such areas, and also elsewhere, should continue to address how the postural and acoustic repertoire of these cetaceans may change in the presence of motorboats. For instance, it is important to determine the approximate distance at which different types of motorboats at different speeds (eg Jensen et al. 2009) start to disturb the postural and vocal behaviour of the estuarine dolphins. Such studies would provide information to set and/or to adjust the size of the protected area, as well as to regulate boat activity in the area, aiming to meet the fundamental requirements for good welfare and conservation of the estuarine dolphins.

\section{Conclusion}

Whistles are of upmost importance in a number of estuarine dolphins' activities, including cooperative foraging. This study showed that the noise produced by motorboats can potentially mask this sound, thus, it points to the most likely explanation for previous findings which show clear disturbances in their behaviour. Last but not least, its results are in accordance with a number of studies conducted on other cetacean species. Precautionary measures aiming towards the conservation and better welfare of the estuarine dolphin call for the establishment of areas protected from the presence of commercial and recreational motorboats.

\section{Acknowledgements}

We are thankful for the logistical support given by David Hassett and Valdenir Andrade at the Pipa Ecological Sanctuary. We are also thankful to three anonymous reviewers for their valuable comments, to Valérie Crouhen (MSc) for observing the boats activity, to Dr. Tacyana Ribeiro who kindly provided the recording equipment and to Fiona Williams (MA) for reviewing the English.

\section{References}

André M (2009) The sperm whale sonar: monitoring and use in mitigation of anthropogenic noise effects in the marine environment. Nuclear Instruments and Methods in Physics Research 602:262-267.

Araújo JP, Passavente JZO, Souto AS (2003) Behavior of the estuarine dolphin, Sotalia guianensis, at Dolphin Bay - Pipa - Rio Grande do Norte - Brazil. Tropical Oceanography 31:101-112.

Araújo JP, Souto AS, Geise L, Araújo ME (2008) The behavior of Sotalia guianensis (Van Bénéden) in Pernambuco coastal waters, Brazil, and further analysis of its reaction to boat traffic. Revista Brasileira de Zoologia $25: 1-9$. 
Bejder L, Dawson SM, Harraway JA (1999) Responses by hector's dolphins to boats and swimmers in Porpoise Bay, New Zealand. Marine Mammal Science 15:738-750.

Bejder L, Samuels A (2003) Evaluating the effects of nature-based tourism on cetaceans. In: Gales N, Hindell M, Kirkwood R (eds) Marine Mammals: Fisheries, Tourism and Management Issues. CSIRO, Collingwood, Australia, pp. 229-251.

Bejder L, Samuels A, Whitehead H, Gales N, Mann J, Connor R, Heithaus M, Watson-Capps J, Flaherty C, Krützen M (2006) Decline of relative abundance of bottlenose dolphins exposed to long-term disturbance. Conservation Biology 20:1791-1798.

Branstetter BK, Finneran JJ (2008) Comodulation masking release in bottlenose dolphins (Tursiops truncatus). Journal of the Acoustical Society of America 124:625-633.

Buckstaff KC (2004) Effects of watercraft noise on the acoustic behavior of bottlenose dolphins, Tursiops truncatus, in Sarasota Bay, Florida. Marine Mammal Science 20:709-725.

Carrera ML, Favaro EGP, Souto AS (2008) The response of marine tucuxis (Sotalia fluviatilis) towards tourist boats involves avoidance behaviour and a reduction in foraging. Animal Welfare 17:117-123.

Constantine $R$ (1999) Effects of tourism on marine mammals in New Zealand. Science for Conservation, 106. Wellington, New Zealand

Constantine R, Brunton DH, Dennis T (2004) Dolphin-watching tour boats change bottlenose dolphin (Tursiops truncatus) behavior. Biological Conservation 117:299-307.

Cooney $R$ (2004) The precautionary principle in biodiversity Conservation and Natural Resource Management: an issues paper for policy-makers, researchers and practitioners. IUCN, Gland, Switzerland and Cambridge, United Kingdom.

David JA (2006) Likely sensitivity of bottlenose dolphins to pile-driving noise. Water and Environment Journal 20:48-54.

Flores PAC (1999) Preliminary results of a photoidentification study of the marine tucuxi, Sotalia fluviatilis, in southern Brazil. Marine Mammal Science 15:840-847.

Foote AD, Osborne RW, Hoelzel AR (2004) Whale-call response to masking boat noise. Nature 428:910.

Garri R (2006) Comportamento de mergulho do boto-cinza, Sotalia guianensis, na Enseada do Curral, Praia da Pipa - RN, Brasil. Possíveis adaptações cardíacas ao mergulho. MSc. Dissertation, Universidade Federal do Rio Grande do Norte, Natal, Rio Grande do Norte, Brazil

Goodwin L, Cotton PA (2004) Effects of boat traffic on the behavior of bottlenose dolphin (Tursiops truncatus). Aquatic Mammals 30:279-283.

Holt MM, Noren DP, Emmons CK (2012) Does vessel noise affect the use of sound by foraging Orcinus orca (killer whales)? In: Arthur N. Popper and Anthony Hawkins (eds) The effects of noise on aquatic life. Springer, New York, USA, pp. 427-430.

Jensen FH, Bejder L, Wahlberg M, Aguilar Soto N, Jonhson M, Madsen PT (2009) Vessel noise effects on delphinid communication. Marine Ecology Progress Series 395:161-175. 
Johnson DH (1999) The insignificance of significance statistical tests. Journal of Wildlife Management 63:763-772.

Laiolo $P(2010)$ The emerging significance of bioacoustics in animal species conservations. Biological Conservation 143:1635-1645.

Lesage V, Barrete C, Kingsley MCS, Sjare B (1999) The effect of vessel noise on the vocal behavior of belugas in the St. Lawrence River Estuary, Canada. Marine Mammal Science 15:65-84.

Lodi LF (2003) Seleção e uso do habitat pelo boto-cinza, Sotalia guianensis (van Bénéden, 1864) (Cetacea, Delphinidae), na Baía de Paraty, Estado do Rio de Janeiro. Bioikos 17:5-20.

Lusseau D (2003) Effects of tour boats on the behavior of bottlenose dolphins: using Markov Chains to model anthropogenic impacts. Conservation Biology 17:1785-1793.

Lusseau D, Higham JES (2004) Managing the impacts of dolphin-based tourism through the definition of critical habitats: the case of bottlenose dolphins (Tursiops spp.) in Doubtful Sound, New Zealand. Tourism Management 25:657-667.

Martins DTL (2010) Caracterização do repertório acústico do boto-cinza, Sotalia guianensis, e impacto de embarcações no nordeste de Brasil. MSc dissertation, Universidade Federal do Rio Grande do Norte, Natal, Rio Grande do Norte, Brazil

May-Collado LJ, Wartzok D (2008) A comparison of bottlenose dolphin whistles in the Atlantic Ocean: factors promoting whistle variation. Journal of Mammalogy 89:1229-1240.

Mundry R, Sommer C (2007) Discriminant function analysis with nonindependent data: consequences and an alternative. Animal Behaviour 74:965-976.

Mortesen LO, Tougaard J, Teilmann J (2011) Effects of underwater noise on harbour porpoises around major shipping lanes. BaltSeaPlan Report 21. Aarhus, Denmark

Nery MF, Espécie MA, Simão SM (2008) Site fidelity of Sotalia guianensis (Cetacea: Delphinidae) in Sepetiba Bay, Rio de Janeiro, Brazil. Revista Brasileira de Zoologia 25:182-187.

Noren DP, Dunkin RC, Williams TM, Holt MM (2012) Energetic cost of behaviors performed in response to vessel disturbance: one link in the population consequences of acoustic disturbance model. In: Arthur N. Popper and Anthony Hawkins (eds) The effects of noise on aquatic life. Springer, New York, USA, pp. 427-430.

Nowacek DP, Tyack PL (2001) A platform for continuous behavioral and acoustic observation of free-ranging marine mammals: overhead video combined with underwater audio. Marine Mammal Science 17:191-199.

Nowacek DP (2005) Acoustic ecology of foraging bottlenose dolphins (Tursiops truncatus), habitat-specific use of three sound types. Marine Mammal Science 21:587-602.

Parsons ECM (2012) The negative impacts of whale-watching. Journal of Marine Biology doi: 10.1155/2012/807294

Pivari D, Rosso S (2005) Whistles of small groups of Sotalia fluviatilis during foraging behavior in southeastern Brazil. Journal of the Acoustical Society of America 118:2725-2731. 
Rezende F (2008) Alterações acústico-comportamentais. In: Monteiro-Filho ELA and Monteiro KDA (eds) Biologia, ecologia e conservação do boto-cinza. Página e Letras Editora Gráfica LTDA, São Paulo, Brazil, pp. 165-176.

Richardson JW, Greene C, Malme C, Thomson D (1995) Marine Mammals and Noise. Academic Press, San Diego, USA

Rook AJ (1999) The use of groups individuals in the design of grazing experiments (reply to Phillips, 1998). Applied Animal Behaviour Science 61:357-358.

Rossi-Santos MR, Podos J (2006) Latitudinal variation in whistle structure of the estuarine dolphin Sotalia guianensis. Behaviour 143:347-364.

Rossi-Santos MR, Wedekin LL, Monteiro-Filho ELA (2007) Residence and site fidelity of Sotalia guianensis in the Caravelas River Estuary, eastern Brazil. Journal of the Marine Biological Association of the United Kingdom 87:207-212.

Santos MCO, Rosso S, Siciliano S, Zerbini A, Zampirolli E, Vicente A, Alvarenga F (2000) Behavioral observations on the marine tucuxi dolphin (Sotalia fluviatilis) in São Paulo estuarine waters, southeastern Brazil. Aquatic Mammals 26:260-267.

Secchi E (2012) Sotalia guianensis. In: IUCN 2012. IUCN Red List of Threatened Species. Version 2012.2. [www.iucnredlist.org] Downloaded on 22 January 2013

Simão SM, Pizzorno JLA, Perry VN, Siciliano S (2000) Aplicação da técnica de fotoidentificação do boto-cinza, Sotalia fluviatilis (Cetacea, Delphinidae) da Baía de Sepetiba. Revista Floresta e Ambiente 7:31-39.

Souto AS, Araújo JP, Geise L, Araújo ME (2006) The surface behavior of the estuarine dolphin in Baía dos Golfinhos, RN, Brazil: a field and comparative study. Revista Brasileira de Zoociências 8:185-194.

Tosi CH, Ferreira RG (2009) Behavior of estuarine dolphin, Sotalia guianensis (Cetacea, Delphinidae), in controlled boat traffic situation at southern coast of Rio Grande do Norte, Brazil. Biodiversity Conservation 18:67-78.

Valle AL, Mello FCC (2006) Alterações comportamentais do golfinho Sotalia guianensis (Gervais, 1953) provocadas por embarcações. Biotemas 19:7580.

Van Parijs SM, Corkeron PJ (2001) Boat traffic affects the acoustic behavior of Pacific humpback dolphins, Sousa chinensis. Journal of the Marine Biological Association of the United Kingdom 81:533-538.

Weary DM, Fraser D (1998) Replications and pseudoreplications: a comment on Phillips. Applied Animal Behaviour Science 61:181-183.

Weilgart LS (2007a) The impacts of anthropogenic ocean noise on cetaceans and implications for management. Canadian Journal of Zoology 85:10911116.

Weilgart LS (2007b) A brief review of known effects of noise on marine mammals. International Journal of Comparative Psychology 20:159-168. 